\title{
Partially naked fluoride in solvate ionic liquids
}

\section{AUTHOR(S):}

Chen, Zhengfei; Tonouchi, Yuto; Matsumoto, Kazuhiko; Saimura, Masayuki; Atkin, Rob; Nagata, Takashi; Katahira, Masato; Hagiwara, Rika

\section{CITATION:}

Chen, Zhengfei ... [et al]. Partially naked fluoride in solvate ionic liquids. Journal of Physical Chemistry Letter 2018, 9(22): 6662-6667

\section{ISSUE DATE:}

2018-11-15

URL:

http://hdl.handle.net/2433/245201

\section{RIGHT:}

This document is the Accepted Manuscript version of a Published Work that appeared in final form in Journal of Physical Chemistry Letter, copyright (C) American Chemical Society after peer review and technical editing by the publisher. To access the final edited and published work see https://doi.org/10.1021/acs.jpclett.8b03117.; この論文は出 版社版でありません。引用の際には出版社版をご確認ご利用ください。; This is not the published version. Please cite only the published version. 


\section{Partially Naked Fluoride in Solvate Ionic Liquids}

Zhengfei Chen, ${ }^{[a]}$ Yuto Tonouchi, ${ }^{[a]}$ Kazuhiko Matsumoto, ${ }^{*[a]}$ Masayuki Saimura, ${ }^{[b]}$ Rob Atkin, ${ }^{[c]}$ Takashi Nagata, ${ }^{[b]}$ Masato Katahira, ${ }^{[b]}$ and Rika Hagiwara ${ }^{[a]}$

${ }^{a}$ Department of Fundamental Energy Science, Graduate School of Energy Science, Kyoto University, Yoshida, Sakyo-ku, Kyoto 606-8501, JAPAN

${ }^{\mathrm{b}}$ Institute of Advanced Energy, Kyoto University, Uji, Kyoto 611-0011, JAPAN

${ }^{\mathrm{c}}$ School of Molecular Sciences, The University of Western Australia, 35 Stirling Highway, Perth, WA 6009, Australia

\section{Corresponding Author}

*k-matsumoto@energy.kyoto-u.ac.jp (Kazuhiko Matsumoto) 
ABSTRACT. Truly naked fluoride only exists in the gas phase. Fluoride can be stabilized by a complexing agent and an organic cation, resulting in anhydrous or dehydrated fluoride which is "partially naked." This partially naked fluoride enables fluorination reactions at much lower temperatures than hydrated fluorides. Here we show a simple method for preparing fluoride based solvate ionic liquids (SILs) by mixing 1-alkyl-3-methylimidazolium (1-ethyl-3methylimidazolium or 1-butyl-3-methylimidazolium) bromide, silver fluoride (AgF), and EG (1:1:1 in molar ratio) in dry methanol. Removal of the methanol produced anhydrous SILs, $\left[\mathrm{C}_{2} \mathrm{C}_{1} \mathrm{im}\right] \mathrm{F} \cdot \mathrm{EG}$ and $\left[\mathrm{C}_{4} \mathrm{C}_{1} \mathrm{im}\right] \mathrm{F} \cdot \mathrm{EG}$. This is the first SIL reported that comprises fluoride. ${ }^{1} \mathrm{H}-\mathrm{NMR}$ and IR spectroscopy reveals fluoride hydrogens bonds with EG OH groups and cation aromatic $\mathrm{H}$ atoms, but not cation tail group protons. Fluorination reactions on benzyl bromide show that $\left[\mathrm{C}_{2} \mathrm{C}_{1} \mathrm{im}\right] \mathrm{F} \cdot \mathrm{EG}$ has high reactivity with reasonable yield under mild conditions, confirming the fluoride ion is partially naked.

\section{TOC GRAPHICS}

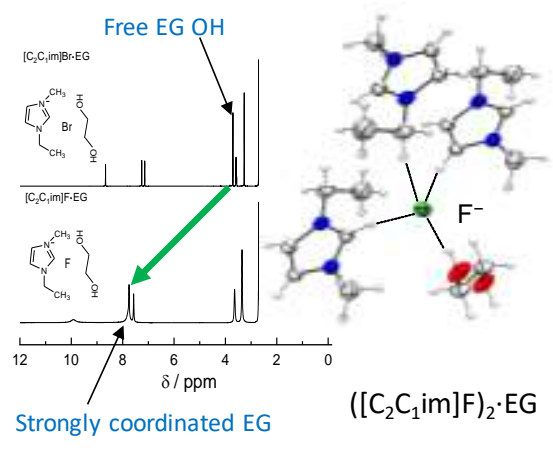

KEYWORDS. Fluorides • Ionic liquids • Hydrogen bonds • Solvation structure • Fluorination 
Fluorination is critical for a wide range of chemical applications in the pharmaceutical, medicinal, and materials sciences, etc. ${ }^{1-2}$ "Naked fluoride" refers to dehydrated (or desolvated) fluoride ions. While gaseous naked fluoride is known, ${ }^{3}$ naked fluoride does not exist in water (or other solvents), as analogous to $\mathrm{H}^{+}$in water, fluoride is always hydrated, or otherwise closely associated with its cation; ${ }^{4}$ if it could be prepared, liquid phase naked fluoride would be extremely basic and have immense catalytic activity. ${ }^{3-6}$ The relative "nakedness" of fluoride is strongly affected by the cation size; the larger size of the cation, the more weakly it associates with the fluoride, and the more naked the fluoride becomes. ${ }^{7}$ This implies that naked fluoride could be obtained from salts of large elemental ions like cesium in aprotic solvents, but in actuality reactions only occur on the solid surface of $\mathrm{CsF}$ because of its low solubility. ${ }^{4}$

An alternative method to hinder fluoride - cation interactions to produce naked fluoride would be to use large organic cations. However, fluoride ions are unstable with most organic cations due to reaction with hydrocarbon $\beta$-hydrogens. ${ }^{6,8-10}$ Fluoride is only stable with organic cations that lack $\beta$-hydrogens, such as tetramethylammonium fluoride (TMAF), ${ }^{9}$ or cations like azabicyclo[2.2.2]octane, where the $\beta$-hydrogen is sterically hindered towards elimination. ${ }^{3}$ However, to produce naked fluoride requires dissolution of these salts in dry aprotic solvents, in which their solubility is very low. Conceivably, these salts could be employed in molten form, but they most likely have high melting point or decompose without forming a liquid phase (decomposition temperature: $170{ }^{\circ} \mathrm{C}$ for TMAF and $140{ }^{\circ} \mathrm{C}$ for azabicyclo[2.2.2]octane fluoride). Attempts to produce ionic liquids (pure salts with low melting points ${ }^{11}$ ) comprising naked fluoride ions have failed; common ionic liquid cations have $\beta$-hydrogens, which the fluoride attacks. ${ }^{12}$ A recent attempt to synthesize an anhydrous dialkylimidazolium fluoride ionic liquids produced a hydrated fluoride anion rather than naked fluoride. ${ }^{5}$ Fluorohydrogenate ionic liquids 
where the anion is a fluoride ion solvated by $\mathrm{HF}$, such as $\left[\mathrm{C}_{2} \mathrm{C}_{1} \mathrm{im}\right]\left[(\mathrm{FH})_{n} \mathrm{~F}\right]\left(\mathrm{C}_{2} \mathrm{C}_{1}\right.$ im ${ }^{+}=1-\mathrm{ethyl}-3-$ methylimidazolium) have low melting point and high ionic conductivity. Unfortunately, the strong F $\cdots \cdot \mathrm{H}$ bond suppresses the activity (nakedness) of the fluoride ion in $(\mathrm{FH})_{n} \mathrm{~F}^{-13-15}$ but nonetheless this suggests the possibility of producing an ionic liquid with naked (or near naked) fluoride by incorporating a hydrogen bond donor (HBD) / ligand weaker than HF. Such an approach shares conceptual similarities of deep eutectic solvents (DESs), ${ }^{16-18}$ where mixing a salt and HBD at an appropriate ratio (often 1:2) produces a low melting point liquid, and solvate ionic liquids (SILs), ${ }^{19-21}$ where mixing a salt and ligand (often a glyme in a 1:1 ratio) also results in a low melting point liquid. For DESs, while a liquid has been prepared by mixing choline fluoride and urea system, the fluoride solvation state (nakedness) and synthetic properties are unclear. ${ }^{16}$ To the authors' knowledge, SILs incorporating fluoride have not been reported.

Here we report a simple method to produce fluoride based SILs comprising 1-alkyl-3methylimidazolium cations, fluoride and ethylene glycol (EG) in a 1:1:1 ratio. Hydrogen bonding between the fluoride and the alcohol groups of ethylene glycol and cation ring hydrogens prevent the fluoride from attacking cation alkyl chain $\beta$-hydrogens, but the fluoride retains sufficient activity to act as a fluorinating agent, demonstrated via the fluorination of benzyl bromide under mild conditions with good yield. The physicochemical properties and solvation structures of the SIL are reported. Combined, these results show the fluoride in these SILs is "partially naked".

The fluoride based SILs were prepared via in one-step by mixing 1-alkyl-3-methylimidazolium (either $\mathrm{C}_{2} \mathrm{C}_{1} \mathrm{im}^{+}$or $\mathrm{C}_{4} \mathrm{C}_{1} \mathrm{im}^{+}$(1-butyl-3-methylimidazolium)) bromide and silver fluoride (AgF), and EG (1:1:1 in molar ratio) in dry methanol. Anhydrous light yellow liquids, $\left[\mathrm{C}_{2} \mathrm{C}_{1} \mathrm{im}\right] \mathrm{F} \cdot \mathrm{EG}$ and $\left[\mathrm{C}_{4} \mathrm{C}_{1} \mathrm{im}\right] \mathrm{F} \cdot \mathrm{EG}$, were obtained by filtration and removal of the dry methanol at a yield of $\sim 100 \%$. Quantitative X-ray fluorescence analysis identified trace amounts of $\mathrm{Ag}(<0.01 \mathrm{~mol} \%)$ and $\mathrm{Br}$ 
$(<0.9 \mathrm{~mol} \%)$ impurities. Differential scanning calorimetry revealed glass transition temperatures of $-71{ }^{\circ} \mathrm{C}$ and $-65{ }^{\circ} \mathrm{C}$ for $\left[\mathrm{C}_{2} \mathrm{C}_{1} \mathrm{im}\right] \mathrm{F} \cdot \mathrm{EG}$ and $\left[\mathrm{C}_{4} \mathrm{C}_{1}\right.$ im $] \mathrm{F} \cdot \mathrm{EG}$, respectively, (Fig.S1a, Supporting Information). This glassy behavior is similar to many conventional ionic liquids ${ }^{11,22-23}$ and SILs. ${ }^{24}$ $\left[\mathrm{C}_{2} \mathrm{C}_{1}\right.$ im] $\mathrm{F} \cdot \mathrm{EG}$ and $\left[\mathrm{C}_{4} \mathrm{C}_{1}\right.$ im $] \mathrm{F} \cdot \mathrm{EG}$ were stable under high vacuum for more than 12 hours. By contrast, over the same period pure EG evaporated, and the mass loss of the corresponding bromide based liquids ( $\sim 0.5 \mathrm{~g}$ ) was about $40 \%$. Thermogravimetric analysis (TGA) (Fig. S1b, Supporting Information) shows $5 \%$ mass loss for $\left[\mathrm{C}_{2} \mathrm{C}_{1} \mathrm{im}\right] \mathrm{F} \cdot \mathrm{EG}$ and $\left[\mathrm{C}_{4} \mathrm{C}_{1} \mathrm{im}\right] \mathrm{F} \cdot \mathrm{EG}$ is not reached until $110^{\circ} \mathrm{C}$ and $143{ }^{\circ} \mathrm{C}$, respectively. Potentially, $\mathrm{HF}$ could form in these liquids if fluoride abstracted a proton from an alcohol group of ethylene glycol. However, it is highly unlikely significant HF is present in either $\left[\mathrm{C}_{2} \mathrm{C}_{1}\right.$ im $] \mathrm{F} \cdot \mathrm{EG}$ or $\left[\mathrm{C}_{4} \mathrm{C}_{1} \mathrm{im}\right] \mathrm{F} \cdot \mathrm{EG}$ because the boiling point of $\mathrm{HF}$ is just $19.5^{\circ} \mathrm{C}$ meaning mass loss would occur at much lower temperatures, and HF would be rapidly removed under vacuum leading to a reduction in the sample mass. Combined, these results show $\left[\mathrm{C}_{2} \mathrm{C}_{1}\right.$ im $] \mathrm{F} \cdot \mathrm{EG}$ and $\left[\mathrm{C}_{4} \mathrm{C}_{1} \mathrm{im}\right] \mathrm{F} \cdot \mathrm{EG}$ have negligible room temperature vapour pressure, are liquids at less than $100^{\circ} \mathrm{C}$, and that physical properties associated with the pure components are not observed, meaning they satisfy 3 key criteria for SILs. ${ }^{25}$

Fluoride solvation by EG and the cation in $\left[\mathrm{C}_{2} \mathrm{C}_{1} \mathrm{im}\right] \mathrm{F} \cdot \mathrm{EG}$ and $\left[\mathrm{C}_{4} \mathrm{C}_{1} \mathrm{im}\right] \mathrm{F} \cdot \mathrm{EG}$ was first probed using ${ }^{19} \mathrm{~F}-\mathrm{NMR}$. The spectra have one signal, at $-113 \mathrm{ppm}$ for $\left[\mathrm{C}_{2} \mathrm{C}_{1} \mathrm{im}\right] \mathrm{F} \cdot \mathrm{EG}$ and $-112 \mathrm{ppm}$ for $\left[\mathrm{C}_{4} \mathrm{C}_{1} \mathrm{im}\right] \mathrm{F} \cdot \mathrm{EG}$ (Fig. S2, Supporting Information). Although this might show there is only one form of fluoride in the liquids, fluoride ions might coordinate with different $\mathrm{H}$ atoms in the SILs as it is not possible to distinguish them by the NMR technique. The similarity of the ${ }^{19}$ F-NMR chemical shifts for $\left[\mathrm{C}_{2} \mathrm{C}_{1} \mathrm{im}\right] \mathrm{F} \cdot \mathrm{EG}$ and $\left[\mathrm{C}_{4} \mathrm{C}_{1} \mathrm{im}\right] \mathrm{F} \cdot \mathrm{EG}$ shows the fluorine solvation environments are essentially the same. This means, as may be expected on polarity grounds, interactions between fluoride and the (different length) cation alkyl chains are minimal. The chemical shifts of -113 
ppm and $-112 \mathrm{ppm}$ are close to those for fluoride solvated by water ( $-119 \mathrm{ppm})$ but significantly downfield of fluoride in methanol $(-149 \mathrm{ppm}) .{ }^{26-27}$ That is, the groups solvating fluorine in $\left[\mathrm{C}_{2} \mathrm{C}_{1} \mathrm{im}\right] \mathrm{F} \cdot \mathrm{EG}$ and $\left[\mathrm{C}_{4} \mathrm{C}_{1} \mathrm{im}\right] \mathrm{F} \cdot \mathrm{EG}$ deshield fluoride electrons to a similar extent as water, and much less than methanol.

Fig. 1 shows infrared (IR) spectra for $\left.\left[\mathrm{C}_{2} \mathrm{C}_{1} \mathrm{im}\right] \mathrm{F} \cdot \mathrm{EG}\right]$ and $\left[\mathrm{C}_{4} \mathrm{C}_{1} \mathrm{im}\right] \mathrm{F} \cdot \mathrm{EG}$ between $500-4000$ $\mathrm{cm}^{-1}$, along with $\left[\mathrm{C}_{2} \mathrm{C}_{1} \mathrm{im}\right] \mathrm{Br} \cdot \mathrm{EG},\left[\mathrm{C}_{4} \mathrm{C}_{1} \mathrm{im}\right] \mathrm{Br} \cdot \mathrm{EG},\left[\mathrm{C}_{2} \mathrm{C}_{1} \mathrm{im}\right] \mathrm{Br}$, and $\mathrm{EG}$ for comparison. The characteristic pure EG OH stretching at $3300 \mathrm{~cm}^{-1}$ is observed in the same region for $\left[\mathrm{C}_{2} \mathrm{C}_{1} \mathrm{im}\right] \mathrm{Br} \cdot \mathrm{EG}$ and $\left[\mathrm{C}_{4} \mathrm{C}_{1} \mathrm{im}\right] \mathrm{Br} \cdot \mathrm{EG}$, but absent for $\left[\mathrm{C}_{2} \mathrm{C}_{1} \mathrm{im}\right] \mathrm{F} \cdot \mathrm{EG}$ and $\left[\mathrm{C}_{4} \mathrm{C}_{1} \mathrm{im}\right] \mathrm{F} \cdot \mathrm{EG}$. For $\mathrm{O}-\mathrm{H}$, $\mathrm{C}-\mathrm{H}$, and $\mathrm{N}-\mathrm{H}$ stretching modes, strong hydrogen bonding leads to band broadening accompanied by a shift to lower frequency. ${ }^{28-30}$ Therefore, red shift of the EG peaks to between 2300 and 2700 $\mathrm{cm}^{-1}$ for $\left[\mathrm{C}_{2} \mathrm{C}_{1} \mathrm{im}\right] \mathrm{F} \cdot \mathrm{EG}$ and $\left[\mathrm{C}_{4} \mathrm{C}_{1} \mathrm{im}\right] \mathrm{F} \cdot \mathrm{EG}$ reveals strong hydrogen bonding between $\mathrm{EG}$ alcohol groups and fluoride.

Increasing the amount of $E G$ in $\left[\mathrm{C}_{2} \mathrm{C}_{1} \mathrm{im}\right]: \mathrm{F}: \mathrm{EG}$ from $1: 1: 1$ to $1: 1: 1.5$ leads to the re-appearance of the EG OH stretching band at around $3350 \mathrm{~cm}^{-1}$ (Fig. S3, Supporting Information), and further increasing $\left[\mathrm{C}_{2} \mathrm{C}_{1} \mathrm{im}\right]: \mathrm{F}: \mathrm{EG}$ from 1:1:2 increases the bands intensity. This indicates the presence of free $\mathrm{EG}$ in the $\left[\mathrm{C}_{2} \mathrm{C}_{1} \mathrm{im}\right]: \mathrm{F}: \mathrm{EG}$ 1:1:1.5 and 1:1:2 $\left[\mathrm{C}_{2} \mathrm{C}_{1} \mathrm{im}\right]: \mathrm{F}: \mathrm{EG}$ liquids. Therefore, the absence of the EG OH stretching band at around $3350 \mathrm{~cm}^{-1}$ in $1: 1: 1$ for $\left[\mathrm{C}_{2} \mathrm{C}_{1} \mathrm{im}\right]: \mathrm{F}: \mathrm{EG}$ shows all the EG in this liquid is complexed with fluoride, which satisfies another criteria for SILs. ${ }^{25}$ 


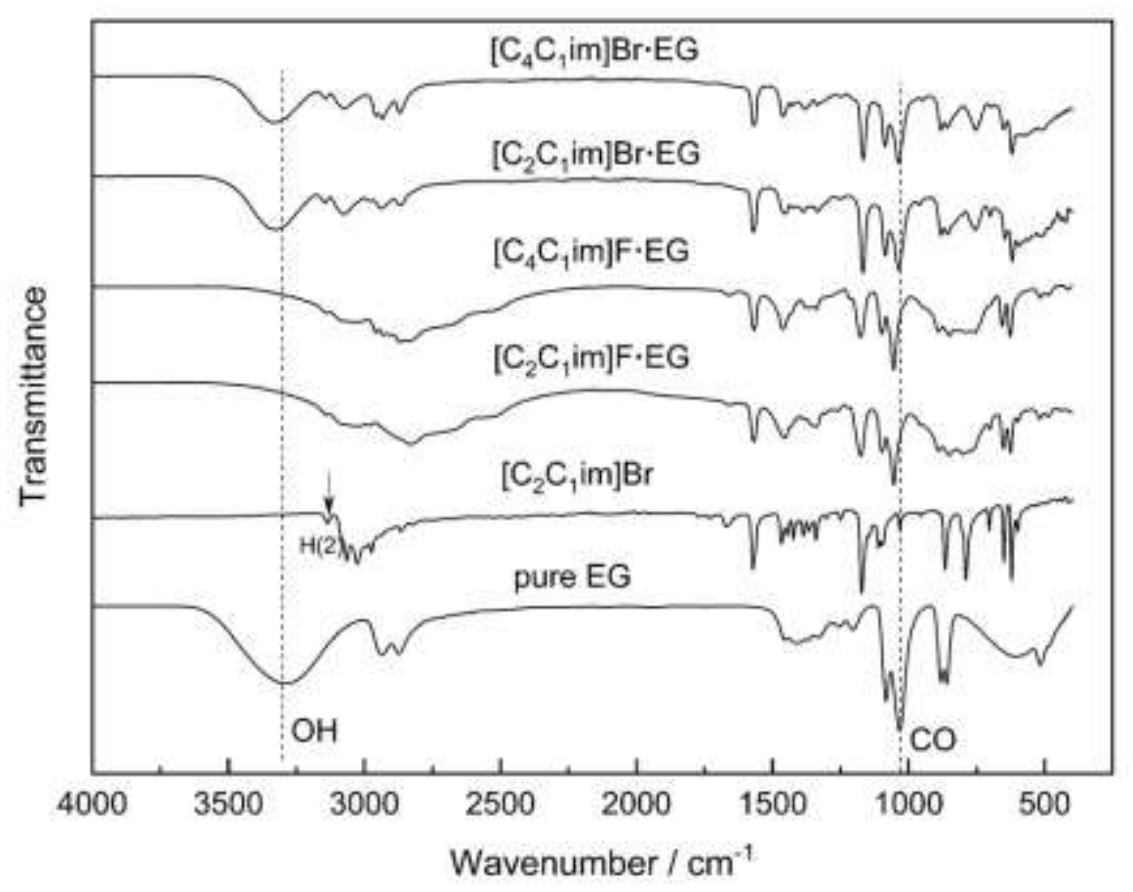

Figure 1. Infrared spectra of $\left.\left[\mathrm{C}_{2} \mathrm{C}_{1} \mathrm{im}\right] \mathrm{F} \cdot \mathrm{EG}\right],\left[\mathrm{C}_{2} \mathrm{C}_{1} \mathrm{im}\right] \mathrm{Br} \cdot \mathrm{EG},\left[\mathrm{C}_{4} \mathrm{C}_{1} \mathrm{im}\right] \mathrm{F} \cdot \mathrm{EG},\left[\mathrm{C}_{4} \mathrm{C}_{1} \mathrm{im}\right] \mathrm{Br} \cdot \mathrm{EG}$, $\left[\mathrm{C}_{2} \mathrm{C}_{1} \mathrm{im}\right] \mathrm{Br}$, and pure $\mathrm{EG}$ at $20^{\circ} \mathrm{C}$.

${ }^{1} \mathrm{H}-\mathrm{NMR}$ measurements were also performed on neat $\left[\mathrm{C}_{2} \mathrm{C}_{1} \mathrm{im}\right] \mathrm{F} \cdot \mathrm{EG}$ and $\left[\mathrm{C}_{4} \mathrm{C}_{1} \mathrm{im}\right] \mathrm{F} \cdot \mathrm{EG}$ to further probe fluoride solvation and exclude other solvent effects. The ${ }^{1} \mathrm{H}-\mathrm{NMR}$ spectra of neat $\left[\mathrm{C}_{2} \mathrm{C}_{1} \mathrm{im}\right] \mathrm{F} \cdot \mathrm{EG}$ and $\left[\mathrm{C}_{4} \mathrm{C}_{1} \mathrm{im}\right] \mathrm{F} \cdot \mathrm{EG}$ are shown in Fig. $2(\mathrm{~A})$ and $(\mathrm{C})$ with atom numbering schemes, along with data for $\left[\mathrm{C}_{2} \mathrm{C}_{1} \mathrm{im}\right] \mathrm{Br} \cdot \mathrm{EG}$ and $\left[\mathrm{C}_{4} \mathrm{C}_{1} \mathrm{im}\right] \mathrm{Br} \cdot \mathrm{EG}$ in Fig. 2 (B) and (D) for comparison. The ${ }^{1} \mathrm{H}-\mathrm{NMR}$ signals are much broader for $\left[\mathrm{C}_{2} \mathrm{C}_{1} \mathrm{im}\right] \mathrm{F} \cdot \mathrm{EG}$ and $\left[\mathrm{C}_{4} \mathrm{C}_{1} \mathrm{im}\right] \mathrm{F} \cdot \mathrm{EG}$ than $\left[\mathrm{C}_{2} \mathrm{C}_{1} \mathrm{im}\right] \mathrm{Br} \cdot \mathrm{EG}$ and $\left[\mathrm{C}_{2} \mathrm{C}_{1} \mathrm{im}\right] \mathrm{Br} \cdot \mathrm{EG}$ due to the higher liquid viscosities. 


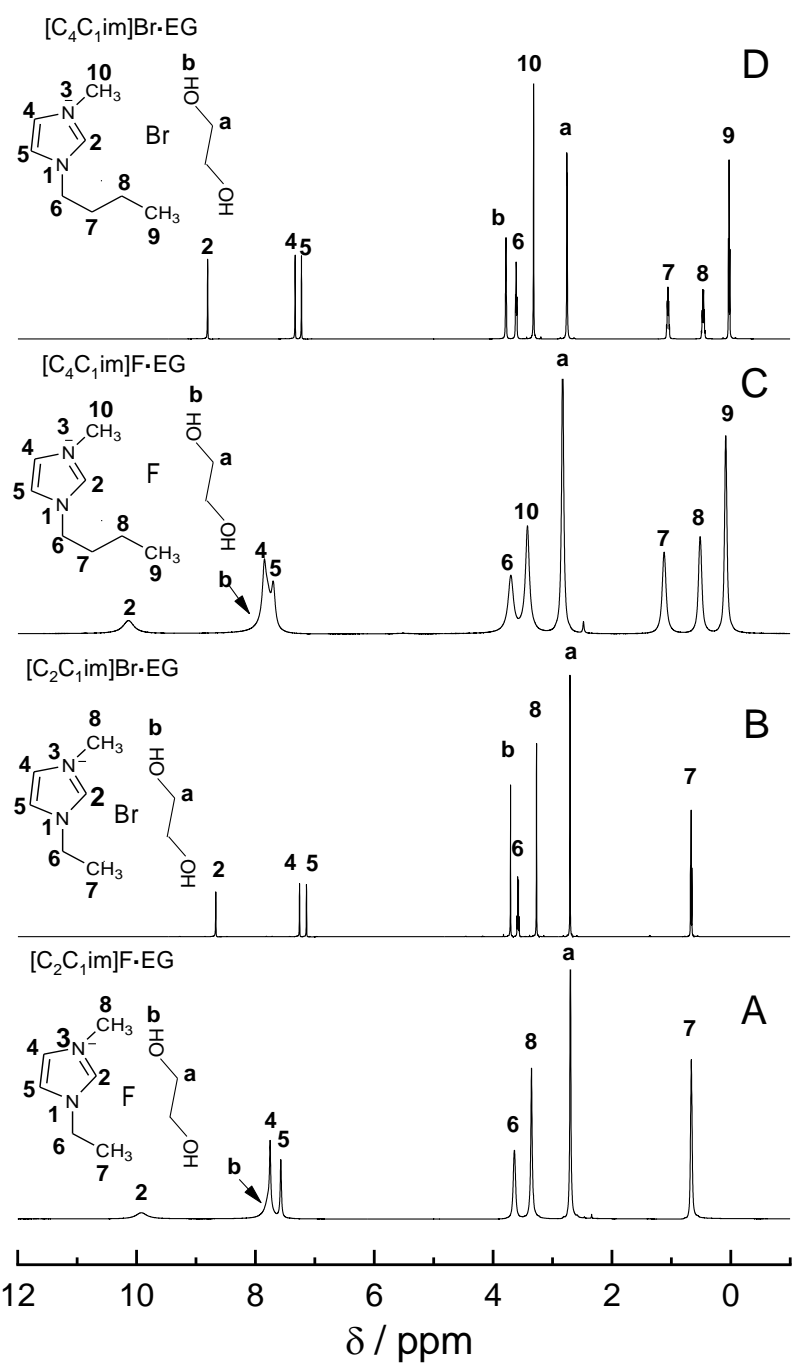

Figure 2. ${ }^{1} \mathrm{H}-\mathrm{NMR}$ spectra of $(\mathrm{A})\left[\mathrm{C}_{2} \mathrm{C}_{1} \mathrm{im}\right] \mathrm{F} \cdot \mathrm{EG},(\mathrm{B})\left[\mathrm{C}_{2} \mathrm{C}_{1} \mathrm{im}\right] \mathrm{Br} \cdot \mathrm{EG},(\mathrm{C})\left[\mathrm{C}_{4} \mathrm{C}_{1} \mathrm{im}\right] \mathrm{F} \cdot \mathrm{EG}$, and (D) $\left[\mathrm{C}_{4} \mathrm{C}_{1}\right.$ im $] \mathrm{Br}-\mathrm{EG}$ at $20^{\circ} \mathrm{C}$.

${ }^{1} \mathrm{H}-\mathrm{NMR}$ signals for EG CH protons (labelled $\mathbf{a}$ in Fig. 2) appear at $2.8 \mathrm{ppm}$ for the four liquids. The EG OH protons (labelled b) are at $3.7 \mathrm{ppm}$ for $\left[\mathrm{C}_{2} \mathrm{C}_{1} \mathrm{im}\right] \mathrm{Br} \cdot \mathrm{EG}$ and $\left[\mathrm{C}_{4} \mathrm{C}_{1} \mathrm{im}\right] \mathrm{Br} \cdot \mathrm{EG}$, slightly downfield of H6 signals, whereas the chemical shift of the $\mathrm{OH}$ protons in pure EG is $4.8 \mathrm{ppm}$. The $1.1 \mathrm{ppm}$ downfield shift in $\left[\mathrm{C}_{2} \mathrm{C}_{1} \mathrm{im}\right] \mathrm{Br} \cdot \mathrm{EG}$ and $\left[\mathrm{C}_{4} \mathrm{C}_{1} \mathrm{im}\right] \mathrm{Br} \cdot \mathrm{EG}$ is attributed to weak hydrogen bonding between EG OH groups and bromide. There is no obvious signal for the EG OH protons in the spectra for the fluoride based liquids, near the H6 signal or otherwise. However, careful 
analysis of the $\left[\mathrm{C}_{2} \mathrm{C}_{1} \mathrm{im}\right] \mathrm{F} \cdot \mathrm{EG}$ and $\left[\mathrm{C}_{4} \mathrm{C}_{1} \mathrm{im}\right] \mathrm{F} \cdot \mathrm{EG}$ spectra reveals the $\mathrm{H} 4$ at $7.7 \mathrm{ppm}$ is broad, and integration of the peak intensities shows three protons contribute to the $\mathrm{H} 4$ signals, not one as expected. This reveals the EG OH proton signal shifts downfield by approximately 4.0 ppm (from 3.7 ppm to 7.7 ppm, c.f. the "b" label in Fig. 2 A and C) and overlaps with H4 due to strong $\mathrm{F}^{-}$ $\cdots \mathrm{HO}$ hydrogen bonds in $\left[\mathrm{C}_{2} \mathrm{C}_{1} \mathrm{im}\right] \mathrm{F} \cdot \mathrm{EG}$ and $\left[\mathrm{C}_{4} \mathrm{C}_{1} \mathrm{im}\right] \mathrm{F} \cdot \mathrm{EG}$. This is consistent with reports that strongly hydrogen bonded protons experience a strong ${ }^{1} \mathrm{H}-\mathrm{NMR}$ downfield shift due to deshielding, ${ }^{31}$ and with the IR data presented above.

The $\left[\mathrm{C}_{2} \mathrm{C}_{1} \mathrm{im}\right]: \mathrm{F}: \mathrm{EG}$ 1:1:1.5 and 1:1:2 $\left[\mathrm{C}_{2} \mathrm{C}_{1} \mathrm{im}\right]: \mathrm{F}: \mathrm{EG}$ samples were also probed using ${ }^{1} \mathrm{H}-\mathrm{NMR}$ (Fig.S4, Supporting Information). The EG OH signal shifts upfield with EG content, from 7.7 ppm for $1 \mathrm{EG}$, to $6.8 \mathrm{ppm}$ for $1.5 \mathrm{EG}$, and $6.2 \mathrm{ppm}$ for $2 \mathrm{EG}$, and peak integration reveals stoichiometric amounts of $\mathrm{OH}$ protons. ${ }^{1} \mathrm{H}-\mathrm{NMR}$ is sensitive to the average state of $\mathrm{EG} \mathrm{OH}$ protons in the liquids. As the EG content increases and there is more free EG, the EG OH proton signal shifts upfield. This is consistent with the IR spectra, which also revealed increased free EG for higher EG ratios in the liquid.

The chemical shift of cation $\mathrm{H} 2$ ring proton for $\left[\mathrm{C}_{2} \mathrm{C}_{1} \mathrm{im}\right] \mathrm{F} \cdot \mathrm{EG}$ and $\left[\mathrm{C}_{4} \mathrm{C}_{1} \mathrm{im}\right] \mathrm{F} \cdot \mathrm{EG}$ shifts downfield ( 10 ppm) by $\sim 1.3 \mathrm{ppm}$ for $\left[\mathrm{C}_{2} \mathrm{C}_{1} \mathrm{im}\right] \mathrm{F} \cdot \mathrm{EG}$ with significant broadening compared to the analogue bromide liquids. The H4 and H5 ring protons also shift downfield, but by just $0.59 \mathrm{ppm}$ and $0.42 \mathrm{ppm}$, respectively, and the signals remain sharp. This data shows fairly strong $\mathrm{F}^{-\cdots} \mathrm{H} 2$ hydrogen bonds form in these liquids consistent with the $\mathrm{H} 2$ proton being the most acidic in these cations. ${ }^{32-33}$ Weaker hydrogen bonds form between fluorine and H4 and H5, but not appreciably with other cation protons.

Increasing the temperature increases the kinetic energy of molecules and ions in a liquid, which weakens hydrogen bonds and increases proton exchange, which deshields protons, resulting in an 
upfield shift. To confirm the presence of $\mathrm{F}^{-\cdots} \mathrm{H} 2, \mathrm{~F}^{-\cdots} \mathrm{H} 4, \mathrm{~F}^{-\cdots} \mathrm{H} 5$ and $\mathrm{F}^{-\cdots} \mathrm{HO}$ hydrogen bonds in $\left[\mathrm{C}_{2} \mathrm{C}_{1} \mathrm{im}\right] \mathrm{F} \cdot \mathrm{EG}$ and $\left[\mathrm{C}_{4} \mathrm{C}_{1} \mathrm{im}\right] \mathrm{F} \cdot \mathrm{EG}$, the effect of temperature on the ${ }^{1} \mathrm{H}-\mathrm{NMR}$ signals associated with these interactions was probed between 5 to $60^{\circ} \mathrm{C}$ (Fig. S5, Supporting Information). The EG $\mathrm{OH}$ and cation ring $(\mathrm{H} 2, \mathrm{H} 4$, and $\mathrm{H} 5)$ protons signals become sharper with decreasing temperature, consistent with hydrogen bonds between these groups and fluoride. All other signals (methyl and methylene protons in the cation and EG) become broader with decreasing temperature owing to increased viscosity.

The picture that emerges for $\left[\mathrm{C}_{2} \mathrm{C}_{1} \mathrm{im}\right] \mathrm{F} \cdot \mathrm{EG}$ and $\left[\mathrm{C}_{4} \mathrm{C}_{1} \mathrm{im}\right] \mathrm{F} \cdot \mathrm{EG}$ is of fluoride complexed by relatively strong hydrogen bonds with the two $\mathrm{EG} \mathrm{OH}$ protons and cation $\mathrm{C} 2$ proton, and weaker hydrogen bonds with cation $\mathrm{H} 4$ and H5 protons. Corresponding bonds in the bromide analogue liquids are weak or absent, consistent with the reduced electronegativity of bromide.

Evidence for stronger hydrogen bonding in the fluoride based liquids is also obtained from macroscopic physical properties. The temperature dependent viscosity, ionic conductivity, and density for $\left[\mathrm{C}_{2} \mathrm{C}_{1} \mathrm{im}\right] \mathrm{F} \cdot \mathrm{EG}$ and $\left[\mathrm{C}_{4} \mathrm{C}_{1} \mathrm{im}\right] \mathrm{F} \cdot \mathrm{EG}$, and the corresponding bromide salts, are shown in Fig. S6 and S7, Supporting Information. Viscosity and ionic conductivity are fitted by the VogelTammann-Fulcher equation ${ }^{34-35}$ with the fitting parameters shown in Table S1 (Supporting Information). ${ }^{36-37}$ The viscosities of $\left[\mathrm{C}_{2} \mathrm{C}_{1} \mathrm{im}\right] \mathrm{F} \cdot \mathrm{EG}$ and $\left[\mathrm{C}_{4} \mathrm{C}_{1} \mathrm{im}\right] \mathrm{F} \cdot \mathrm{EG}$ at $25{ }^{\circ} \mathrm{C}$ are 575 and 1044 $\mathrm{mPa}$ s, respectively. This is an order of magnitude higher than for the bromide analogues, which have viscosities of 35 and $74 \mathrm{mPa}$ s for $\left[\mathrm{C}_{2} \mathrm{C}_{1} \mathrm{im}\right] \mathrm{Br} \cdot \mathrm{EG}$ and $\left[\mathrm{C}_{4} \mathrm{C}_{1} \mathrm{im}\right] \mathrm{Br} \cdot \mathrm{EG}$, respectively. This difference is consistent with much stronger interactions in the fluoride-based liquids. This is also reflected in the low diffusion coefficients measured by pulsed-gradient field spin-echo (PGSE)NMR for $\mathrm{C}_{2} \mathrm{C}_{1} \mathrm{im}^{+}$and EG $\left(3.4 \times 10^{-7}\right.$ and $2.6 \times 10^{-7} \mathrm{~cm}^{2} \mathrm{~s}^{-1}$ at $40^{\circ} \mathrm{C}$, respectively) $\left(c f .8 .0 \times 10^{-7}\right.$ and $6.8 \times 10^{-7} \mathrm{~cm}^{2} \mathrm{~s}^{-1}$ for $\mathrm{C}_{2} \mathrm{C}_{1} \mathrm{im}^{+}$and $\mathrm{BF}_{4}^{-}$in $\left[\mathrm{C}_{2} \mathrm{C}_{1} \mathrm{im}\right]\left[\mathrm{BF}_{4}\right]$ at $\left.40{ }^{\circ} \mathrm{C}\right) .{ }^{38}$ These values increase upon 
by heating to $7.8 \times 10^{-7}$ and $7.2 \times 10^{-7} \mathrm{~cm}^{2} \mathrm{~s}^{-1}$ at $60^{\circ} \mathrm{C}$. As expected, ionic conductivity is inversely related to viscosity, ${ }^{37}$ and increases in the order of $\left[\mathrm{C}_{4} \mathrm{C}_{1}\right.$ im $] \mathrm{F} \cdot \mathrm{EG}<\left[\mathrm{C}_{2} \mathrm{C}_{1}\right.$ im $] \mathrm{F} \cdot \mathrm{EG}<$ $\left[\mathrm{C}_{4} \mathrm{C}_{1} \mathrm{im}\right] \mathrm{Br} \cdot \mathrm{EG}<\left[\mathrm{C}_{2} \mathrm{C}_{1} \mathrm{im}\right] \mathrm{Br} \cdot \mathrm{EG}$. The ionic conductivities of $\left[\mathrm{C}_{2} \mathrm{C}_{1} \mathrm{im}\right] \mathrm{F} \cdot \mathrm{EG}$ and $\left[\mathrm{C}_{4} \mathrm{C}_{1} \mathrm{im}\right] \mathrm{F} \cdot \mathrm{EG}$ at $25{ }^{\circ} \mathrm{C}$ are 1.03 and $0.35 \mathrm{mS} \mathrm{cm}{ }^{-1}$, respectively, which is similar to ionic liquids ${ }^{39-40}$ and deep eutectic solvents ${ }^{41}$ with similar viscosities.

About 1 month after synthesis, a few crystals precipitated from $\left[\mathrm{C}_{2} \mathrm{C}_{1} \mathrm{im}\right] \mathrm{F} \cdot \mathrm{EG}$, indicating this liquid is meta-stable at room temperature. Some well-known traditional ionic liquids are also meta stable at room temperature, for example, ethanolammonium nitrate ${ }^{42}$ The crystals formed were found to have a composition in $\left[\mathrm{C}_{2} \mathrm{C}_{1} \mathrm{im}\right]: \mathrm{F}: \mathrm{EG}$ as 1:1:0.5 $\left(\left(\left[\mathrm{C}_{2} \mathrm{C}_{1} \mathrm{im}\right] \mathrm{F}\right)_{2} \cdot \mathrm{EG}\right)$ which had a melting point of $85{ }^{\circ} \mathrm{C}$, but decomposition occurred almost simultaneously, c.f. Fig. S8, Supporting Information. No crystals were present in $\left[\mathrm{C}_{4} \mathrm{C}_{1} \mathrm{im}\right] \mathrm{F} \cdot \mathrm{EG}$ several months after synthesis.

Although the $\left[\mathrm{C}_{2} \mathrm{C}_{1} \mathrm{im}\right] \mathrm{F} \cdot \mathrm{EG}$ liquid structure is dynamic, the structure of the crystals recovered provide an indication of the favoured interactions. Fig. 3 shows the X-ray crystal structure of $\left(\left[\mathrm{C}_{2} \mathrm{C}_{1} \mathrm{im}\right] \mathrm{F}\right)_{2} \cdot \mathrm{EG}$ (see Tables S2 and S3 for crystallographic data and selected geometrical parameters). The coordination environment of fluoride ion is best described as distorted tetrahedron $\left(82.5^{\circ}<\mathrm{H}^{\cdots} \mathrm{F}^{-} \cdots \mathrm{H}\right.$ angle $\left.<137.0^{\circ}\right)$, with the fluoride surrounded by two aromatic hydrogen atoms, one methylene hydrogen atom, and one $\mathrm{OH}$ hydrogen (Fig. 3(b)). The $\mathrm{F}^{-} \cdots \mathrm{HO}$ distance is $1.66 \AA$, which is similar to the value of $1.598 \AA$ of $\mathrm{F}^{-} \cdot \mathrm{HO}$ reported for $\mathrm{KF} \cdot \mathrm{CH}_{2}\left(\mathrm{CO}_{2} \mathrm{H}\right)_{2},{ }^{43}$ and significantly shorter than the sum of the van der Waals distances of hydrogen and fluorine atoms $(2.7 \AA) .{ }^{44}$ The $\mathrm{F} 1 \cdots \mathrm{H} 2$ distance $(1.88 \AA)$ is shorter than the F1 $\cdots \mathrm{H} 4$ distance $(2.08 \AA$ ), and the fluoride to methylene hydrogen atom (H6a) distance is long (2.23 $\AA$ ), revealing a weak interaction. Interactions between atoms are inversely correlated with bond 
strength, so these differences reflect the strength of $\mathrm{F} \cdots \mathrm{H}$ interactions, and agree well with the proton acidities. ${ }^{32-33}$

In the crystal, the EG molecule adopts a trans conformation (see Fig. S9a, Supporting Information), with the $\mathrm{O}-\mathrm{C}-\mathrm{C}-\mathrm{O}$ angle being crystallographically restricted to be $180^{\circ}$, as observed in pure EG crystal. ${ }^{45}$ The EG bridges two $\mathrm{C}_{2} \mathrm{C}_{1} \mathrm{im}^{+}$cations through the $\mathrm{F}^{-} \cdots \mathrm{HO}$ interactions (see Fig. S9b, Supporting Information for the packing diagram). The oxygen atom in the $\mathrm{OH}$ group has a short contact with $\mathrm{H} 5$ aromatic hydrogen atom $(\mathrm{O} \cdots \mathrm{H}$ distance of $2.30 \AA$ ), which may also contribute to the stabilization of this system in the liquid state. The crystallographic model suggests the order of hydrogen bonding strength: $\mathrm{OH}$ proton $>\mathrm{H} 2>\mathrm{H} 4 \approx \mathrm{H} 5>\mathrm{H} 6$, which agrees with the NMR results. Although the gauche conformer of EG molecule with the $\mathrm{O}-\mathrm{C}-\mathrm{C}-\mathrm{O}$ angle $\approx 60^{\circ}$ may be possible, stereochemical repulsion does not allow the bidentate coordination to fluoride ion. If this persists in the liquid state, this will create three dimensional hydrogen bond networks in $\left[\mathrm{C}_{2} \mathrm{C}_{1} \mathrm{im}\right] \mathrm{F} \cdot \mathrm{EG}$ and $\left[\mathrm{C}_{4} \mathrm{C}_{1} \mathrm{im}\right] \mathrm{F} \cdot \mathrm{EG}$. 

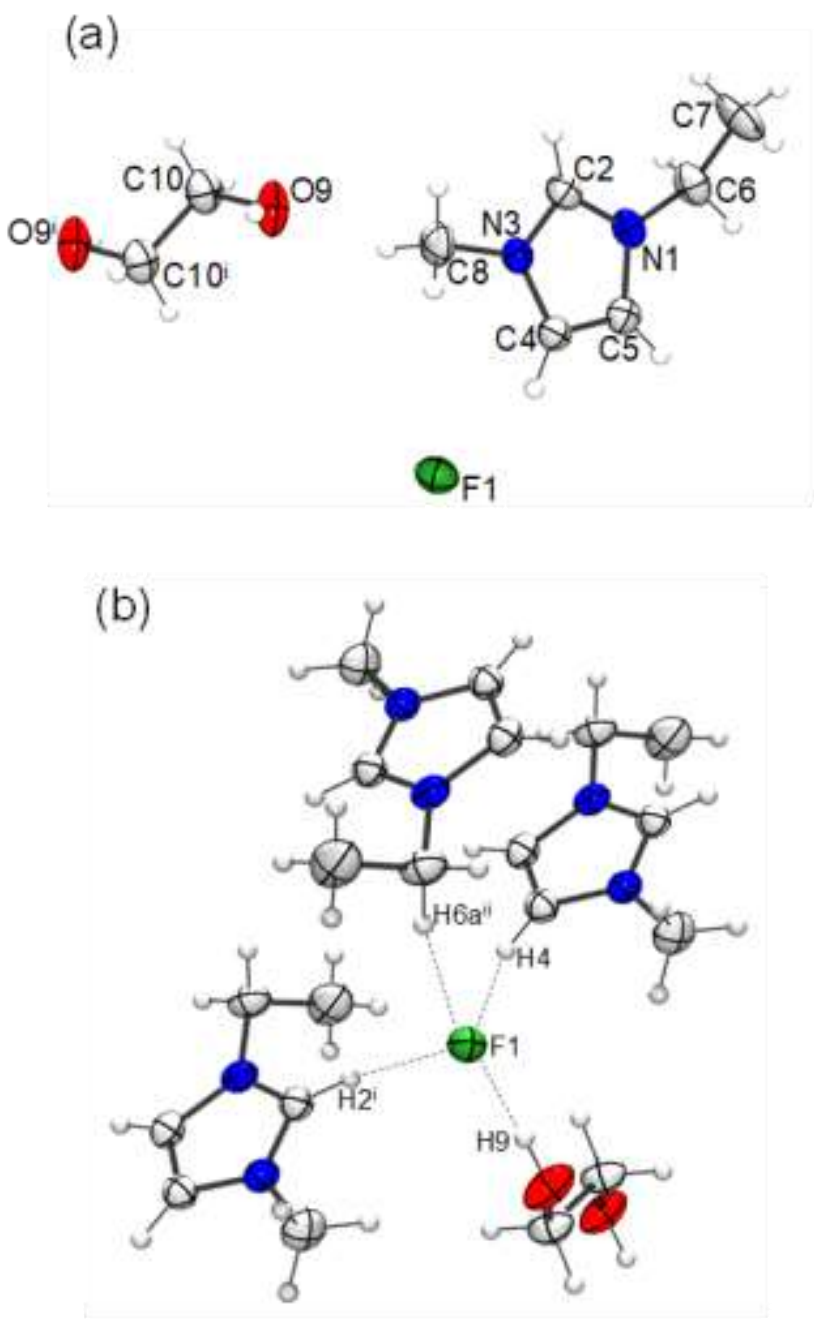

Figure 3. X-ray crystal structures of $\left(\left[\mathrm{C}_{2} \mathrm{C}_{1} \mathrm{im}\right] \mathrm{F}\right)_{2} \cdot \mathrm{EG}$. (a) asymmetric unit [symmetric code: (i) $-x, 1-y, 2-z$ ] and (b) coordination environment of $\mathrm{F}^{-}$[symmetric code: (i) $1+x, y, z$; (ii) 1-x, 1-y,

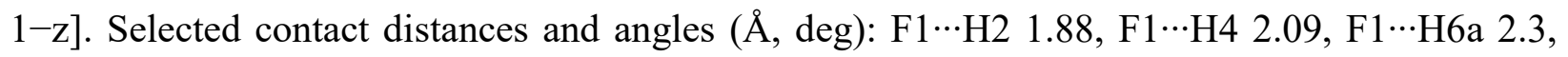

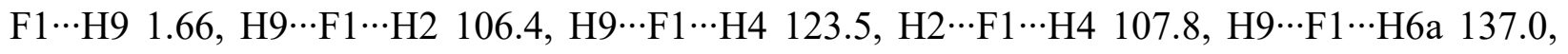
H2 $\cdots \mathrm{F} 1 \cdots \mathrm{H} 6 \mathrm{a} 94.6, \mathrm{H} 4 \cdots \mathrm{F} 1 \cdots \mathrm{H} 6 \mathrm{a}, 82.5$. Green: fluorine, blue: nitrogen red: oxygen, gray: carbon and hydrogen.

Typical fluorination reactions require high temperatures and longer times using alkali metal fluorides, which are poorly soluble in organic solvents. ${ }^{2}$ In order to assess how naked (available) 
the fluoride ion is for reaction in these liquids, the reactivity of $\left[\mathrm{C}_{2} \mathrm{C}_{1} \mathrm{im}\right] \mathrm{F} \cdot \mathrm{EG}$ was studied via fluorination reactions with benzyl bromide with and without solvent (DMF) at two different molar ratios of fluoride to bromide (1 or 1.5 ) at room temperature. $\left[\mathrm{C}_{2} \mathrm{C}_{1} \mathrm{im}\right] \mathrm{F} \cdot \mathrm{EG}$ was stable in DMF as confirmed by the ${ }^{1} \mathrm{H}$ and ${ }^{19} \mathrm{~F}-\mathrm{NMR}$ results (Fig.S10, Supporting Information). The reaction mixtures were stirred at room temperature for $2 \mathrm{~h}$, resulting in a colorless solution. The conversion of benzyl bromide and the yield of product was determined by ${ }^{1} \mathrm{H}$ and ${ }^{19} \mathrm{~F}$ NMR results, respectively, (see Fig.S11 and S12, Supporting Information), are shown in Table 1. At equimolar ratios of $\left[\mathrm{C}_{2} \mathrm{C}_{1} \mathrm{im}\right] \mathrm{F} \cdot \mathrm{EG}$, fluorination of benzyl bromide was incomplete, resulting in a relatively low yield $(<50 \%)$, both with and without DMF. Increasing the equivalent molar benzyl bromide: $\left[\mathrm{C}_{2} \mathrm{C}_{1} \mathrm{im}\right] \mathrm{F} \cdot \mathrm{EG}$ to $1: 1.5$ increased conversion to $98 \%$ and the yield of benzyl fluoride to $\sim 60 \%$. This shows that the fluoride in $\left[\mathrm{C}_{2} \mathrm{C}_{1} \mathrm{im}\right] \mathrm{F} \cdot \mathrm{EG}$ is, at least, partially naked.

Table 1. Fluorination reaction of benzyl bromide with $\left[\mathrm{C}_{2} \mathrm{C}_{1} \mathrm{im}\right] \mathrm{F} \cdot \mathrm{EG}$.

\begin{tabular}{llll}
\hline & equiv of $\left[\mathrm{C}_{2} \mathrm{C}_{1} \mathrm{im}\right] \mathrm{F} \cdot \mathrm{EG}$ & Conversion $(\%)^{\mathrm{a}}$ & Yield $(\%)^{\mathrm{b}}$ \\
\hline entry & 1 & 62 & 48 \\
1 & 1.5 & 99 & 62 \\
3 & 1 in DMF & 81 & 41 \\
4 & 1.5 in DMF & 98 & 58 \\
\hline
\end{tabular}


${ }^{a}$ The conversion rate was determined by the unreacted benzyl bromide estimated from the ${ }^{1} \mathrm{H}$ NMR of final products. ${ }^{b}$ Yield was estimated by the ${ }^{19} \mathrm{~F}$ NMR results by adding known amount of 1,3,5-trifluorobenzene as an internal standard.

The $\sim 60 \%$ yield of the benzyl fluoride obtained here is lower than the $\sim 70 \%$ yield recently reported for a quaternary ammonium fluoride based on azabicyclo[2.2.2]octane, ${ }^{3}$ but this fluorination agent requires the use of volatile, toxic, organic solvents (ACN, DMSO, etc). Fluorination achieved here in similar yield in the nonvolatile $\left[\mathrm{C}_{2} \mathrm{C}_{1} \mathrm{im}\right] \mathrm{F} \cdot \mathrm{EG}$ liquid without added solvent in just 2 hours without the use of a quenching agent, which represent significant advantages. Further, the stability of $\left[\mathrm{C}_{2} \mathrm{C}_{1} \mathrm{im}\right] \mathrm{F} \cdot \mathrm{EG}$ in $\mathrm{DMF}$ opens possibilities for many potential fluorination reactions with other organics.

In conclusion, new fluoride based solvate fluoride ionic liquids, $\left[\mathrm{C}_{2} \mathrm{C}_{1} \mathrm{im}\right] \mathrm{F} \cdot \mathrm{EG}$ and $\left[\mathrm{C}_{4} \mathrm{C}_{1} \mathrm{im}\right] \mathrm{F} \cdot \mathrm{EG}$, synthesized by reaction of the respective bromide salts, silver fluoride and EG. The liquids have negligible room temperature vapour pressure, have melting points less than $100^{\circ} \mathrm{C}$, all of the EG is associated with fluoride ions, and exhibit no physical properties associated with the pure components, thereby satisfying the criteria for SILs. NMR and IR reveal strong hydrogen bonding between fluoride ion and EG molecules, and with the imidazolium ring proton (H2), along with weaker interactions with the cation ring $\mathrm{H} 4$ and H5. No interactions are noted between fluorine and cation alkyl chain protons, raising the possibility that the SIL is nanostructured; this is the topic of further study. X-ray diffraction of crystal precipitated from the meta stable $\left[\mathrm{C}_{2} \mathrm{C}_{1} \mathrm{im}\right] \mathrm{F} \cdot \mathrm{EG}$ show the fluoride binds to two EG molecules in the crystal. If this persists in the liquid state, this will create a three dimensional hydrogen bond network that may support surfactant self assembly. The reactivity of $\left[\mathrm{C}_{2} \mathrm{C}_{1} \mathrm{im}\right] \mathrm{F} \cdot \mathrm{EG}$ was examined by fluorination of benzyl bromide with a reasonable yield both in neat form and in DMF, which opens high potential 
application of $\left[\mathrm{C}_{\mathrm{n}} \mathrm{C}_{1} \mathrm{im}\right] \mathrm{F} \cdot \mathrm{EG}$ in organic reactions (currently underway). This reveals the fluoride in $\left[\mathrm{C}_{2} \mathrm{C}_{1} \mathrm{im}\right] \mathrm{F} \cdot \mathrm{EG}$ and $\left[\mathrm{C}_{4} \mathrm{C}_{1} \mathrm{im}\right] \mathrm{F} \cdot \mathrm{EG}$ is partially naked.

\section{ASSOCIATED CONTENT}

Supporting Information. The Supporting Information is available free of charge on the ACS Publications website at DOI: 10.1021/acs.inorg-chem.xxxxxxx. Experimental details and crystallographic, spectroscopic, and thermoanalytical data (PDF).

Accession Codes. CCDC 1870396 contains the supplementary crystallographic data for this paper. These data can be obtained free of charge via www.ccdc.cam.ac.uk/data_request/cif, or by emailing data_request@ccdc.cam.ac.uk, or by contacting The Cambridge Crystallographic Data Centre, 12 Union Road, Cambridge CB21EZ, UK; fax: +44 1223336033.

\section{AUTHOR INFORMATION}

\section{Corresponding Author}

*k-matsumoto@energy.kyoto-u.ac.jp (Kazuhiko Matsumoto)

Notes

The authors declare no competing financial interests.

\section{ACKNOWLEDGMENT}

Z.C. acknowledges the International Fellowship (P17717) from the Japan Society for the Promotion of Science (JSPS). This work was financially supported by the Grant-in-Aid for Scientific Research (17F17717). 


\section{REFERENCES}

1. $\mathrm{Xu}, \mathrm{X} .-\mathrm{H} . ;$ Matsuzaki, K.; Shibata, N., Synthetic Methods for Compounds Having $\mathrm{CF}_{3}-\mathrm{S}$

Units on Carbon by Trifluoromethylation, Trifluoromethylthiolation, Triflylation, and Related Reactions. Chem. Rev. 2015, 115, 731-764.

2. Yerien, D. E.; Bonesi, S.; Postigo, A., Fluorination Methods in Drug Discovery. Org. Biomol. Chem. 2016, 14, 8398-8427.

3. Elias, S.; Karton-Lifshin, N.; Yehezkel, L.; Ashkenazi, N.; Columbus, I.; Zafrani, Y., Synthesis, Characterization, and Reactivity of Thermally Stable Anhydrous Quaternary Ammonium Fluorides. Org. Lett. 2017, 19, 3039-3042.

4. Seppelt, K., Does the Naked Fluoride Ion Exist? Angew Chem Int Ed 1992, 31, 292-293.

5. Bouvet, S.; Pegot, B.; Marrot, J.; Magnier, E., Solvent Free Nintroduction of Fluorine with Bmim F. Tetrahedron Lett. 2014, 55, 826-829.

6. Cox, D. P.; Terpinski, J.; Lawrynowicz, W., "Anhydrous" Tetrabutylammonium Fluoride: A Mild but Highly Efficient Source of Nucleophilic Fluoride Ion. J. Org. Chem. 1984, 49, 32163219.

7. Christe, K. O.; Brooke Jenkins, H. D., Quantitative Measure for the "Nakedness" of Fluoride Ion Sources J. Am. Chem. Soc. 2003, 125, 14210-14210.

8. Zaikin, P.; Dyan, O.; Evtushok, D.; Usoltsev, A.; Borodkin, G.; Karpova, E.; Shubin, V., Solvent-Free Fluorination of Electron-Rich Aromatic Compounds with F-TEDA-BF 4 : Toward “Dry” Processes. Eur. J. Org. Chem. 2017, 2017, 2469-2474.

9. Christe, K. O.; Wilson, W. W.; Wilson, R. D.; Bau, R.; Feng, J. A., Syntheses, Properties, and Structures of Anhydrous Tetramethylammonium Fluoride and Its 1-1 Adduct with Trans-3Amino-2-Butenenitrile. J. Am. Chem. Soc. 1990, 112, 7619-7625. 
10. Gnann, R. Z.; Wagner, R. I.; Christe, K. O.; Bau, R.; Olah, G. A.; Wilson, W. W., Naked fluoride ion sources: Synthesis, characterization, and coupling reaction of Lmethylhexamethylenetetramine fluoride. J. Am. Chem. Soc. 1997, 119, 112-115.

11. Welton, T., Ionic liquids in catalysis. Coord. Chem. Rev. 2004, 248, 2459-2477.

12. Matsumoto, K.; Hagiwara, R.; Yoshida, R.; Ito, Y.; Mazej, Z.; Benkič, P.; Žemva, B.; Tamada, O.; Yoshino, H.; Matsubara, S., Syntheses, Structures and Properties of 1-Ethyl-3Methylimidazolium Salts of Fluorocomplex Anions. Dalton Trans. 2004, 144-149.

13. Xu, F.; Matsumoto, K.; Hagiwara, R., Effects of Alkyl Chain Length on Properties of 1Alkyl-3-methylimidazolium Fluorohydrogenate Ionic Liquid Crystals. Chemistry - A European Journal 2010, 16, 12970-12976.

14. Matsumoto, K.; Hagiwara, R., Chapter 5 - Fluorohydrogenate Ionic Liquids, Liquid Crystals, and Plastic Crystals. In Advanced Fluoride-Based Materials for Energy Conversion, Nakajima, T.; Groult, H., Eds. Elsevier: 2015; pp 103-123.

15. Hagiwara, R.; Hirashige, T.; Tsuda, T.; Ito, Y., Acidic 1-Ethyl-3-Methylimidazolium Fluoride: A New Room Temperature Ionic Liquid. J. Fluorine Chem. 1999, 99, 1-3.

16. Abbott, A. P.; Capper, G.; Davies, D. L.; Rasheed, R. K.; Tambyrajah, V., Novel Solvent Properties of Choline Chloride/urea Mixtures. Chem. Commun. 2003, 70-71.

17. Smith, E. L.; Abbott, A. P.; Ryder, K. S., Deep Eutectic Solvents (DESs) and Their Applications. Chem. Rev. 2014, 114, 11060-11082.

18. Chen, Z.; Greaves, T. L.; Warr, G. G.; Atkin, R., Mixing Cations with Different Alkyl Chain Lengths Markedly Depresses the Melting Point in Deep Eutectic Solvents Formed from Alkylammonium Bromide Salts and Urea. Chem. Commun. 2017, 53, 2375-2377. 
19. Tamura, T.; Yoshida, K.; Hachida, T.; Tsuchiya, M.; Nakamura, M.; Kazue, Y.; Tachikawa, N.; Dokko, K.; Watanabe, M., Physicochemical Properties of Glyme\&ndash;Li Salt Complexes as a New Family of Room-temperature Ionic Liquids. Chem. Lett. 2010, 39, 753-755.

20. Chen, Z.; FitzGerald, P. A.; Warr, G. G.; Atkin, R., Conformation of Poly(ethylene oxide) Dissolved in the Solvate Ionic Liquid [Li(G4)]TFSI. Phys. Chem. Chem. Phys. 2015, 17, 1487214878.

21. Chen, Z.; McDonald, S.; Fitzgerald, P. A.; Warr, G. G.; Atkin, R., Structural Effect of Glyme-Li ${ }^{+}$Salt Solvate Ionic Liquids on the Conformation of Poly(ethylene oxide). Phys. Chem. Chem. Phys. 2016, 18, 14894-14903.

22. Zhang, S.; Sun, N.; He, X.; Lu, X.; Zhang, X., Physical Properties of Ionic Liquids: Database and Evaluation. J. Phys. Chem. Ref. Data 2006, 35, 1475-1517.

23. Greaves, T. L.; Drummond, C. J., Protic Ionic Liquids: Properties and Applications. Chem. Rev. 2008, 108, 206-237.

24. Ueno, K.; Yoshida, K.; Tsuchiya, M.; Tachikawa, N.; Dokko, K.; Watanabe, M., GlymeLithium Salt Equimolar Molten Mixtures: Concentrated Solutions or Solvate Ionic Liquids? J. Phys. Chem. B 2012, 116, 11323-11331.

25. Mandai, T.; Yoshida, K.; Ueno, K.; Dokko, K.; Watanabe, M., Criteria for Solvate Ionic Liquids. Phys. Chem. Chem. Phys. 2014, 16, 8761-8772.

26. Gerken, M.; Boatz, J. A.; Kornath, A.; Haiges, R.; Schneider, S.; Schroer, T.; Christe, K. O., The ${ }^{19}$ F NMR Shifts Are Not A Measure for the Nakedness of the Fluoride Anion. J. Fluorine Chem. 2002, 116, 49-58.

27. Kornath, A.; Neumann, F.; Oberhammer, H., Tetramethylphosphonium Fluoride: "Naked" Fluoride and Phosphorane. Inorg. Chem. 2003, 42, 2894-2901. 
28. Dieter, K. M.; Dymek, C. J.; Heimer, N. E.; Rovang, J. W.; Wilkes, J. S., Ionic Structure and Interactions in 1-Methyl-3-Ethylimidazolium Chloride-Aluminum Chloride Molten Salts. $J$. Am. Chem. Soc. 1988, 110, 2722-2726.

29. Tait, S.; Osteryoung, R. A., Infrared Study of Ambient-temperature Chloroaluminates as A Function of Melt Acidity. Inorg. Chem. 1984, 23, 4352-4360.

30. Barlow, S. J.; Bondarenko, G. V.; Gorbaty, Y. E.; Yamaguchi, T.; Poliakoff, M., An IR Study of Hydrogen Bonding in Liquid and Supercritical Alcohols. J. Phys. Chem. A 2002, 106, 10452-10460.

31. Del Bene, J. E.; Perera, S. A.; Bartlett, R. J., Hydrogen Bond Types, Binding Energies, and 1H NMR Chemical Shifts. J. Phys. Chem. A 1999, 103, 8121-8124.

32. Amyes, T. L.; Diver, S. T.; Richard, J. P.; Rivas, F. M.; Toth, K., Formation and Stability of N-Heterocyclic Carbenes in Water: The Carbon Acid pKa of Imidazolium Cations in Aqueous Solution. J. Am. Chem. Soc. 2004, 126, 4366-4374.

33. Dymek, C. J.; Grossie, D. A.; Fratini, A. V.; Wade Adams, W., Evidence for the Presence of Hydrogen-Bonded Ion-Ion Interactions in the Molten Salt Precursor, 1-Methyl-3Ethylimidazolium Chloride. J. Mol. Struct. 1989, 213, 25-34.

34. Vogel, H., The Temperature Dependence Law of the Viscosity of Fluids. Phys. Zeit. 22 1921, 645-646.

35. Fulcher, G. S., Analysis of Recent Measurements of the Viscosity of Glasses. J. Am. Ceram. Soc. 1925, 8, 339-355.

36. Shi, C.; Quiroz-Guzman, M.; DeSilva, A.; Brennecke, J. F., Physicochemical and Electrochemical Properties of Ionic Liquids Containing Aprotic Heterocyclic Anions Doped With Lithium Salts. J. Electrochem. Soc. 2013, 160, A1604-A1610. 
37. Xu, W.; Cooper, E. I.; Angell, C. A., Ionic Liquids: Ion Mobilities, Glass Temperatures, and Fragilities. J. Phys. Chem. B 2003, 107, 6170-6178.

38. Noda, A.; Hayamizu, K.; Watanabe, M., Pulsed-Gradient Spin-Echo ${ }^{1} \mathrm{H}$ and ${ }^{19}$ F NMR Ionic Diffusion Coefficient, Viscosity, and Ionic Conductivity of Non-Chloroaluminate RoomTemperature Ionic Liquids. J. Phys. Chem. B 2001, 105, 4603-4610.

39. Zech, O.; Stoppa, A.; Buchner, R.; Kunz, W., The Conductivity of Imidazolium-Based Ionic Liquids from (248 to 468) K. B. Variation of the Anion. J. Chem. Eng. Data 2010, 55, 17741778.

40. Widegren, J. A.; Saurer, E. M.; Marsh, K. N.; Magee, J. W., Electrolytic conductivity of four imidazolium-based room-temperature ionic liquids and the effect of a water impurity. J. Chem. Thermodyn. 2005, 37, 569-575.

41. Zhang, Q. H.; Vigier, K. D.; Royer, S.; Jerome, F., Deep Eutectic Solvents: Syntheses, Properties and Applications. Chem. Soc. Rev. 2012, 41, 7108-7146.

42. Greaves, T. L.; Weerawardena, A.; Fong, C.; Krodkiewska, I.; Drummond, C. J., Protic Ionic Liquids: Solvents with Tunable Phase Behavior and Physicochemical Properties. J. Phys. Chem. B 2006, 110, 22479-22487.

43. Emsley, J.; Jones, D. J.; Kuroda, R., Deuteriation of An Asymmetric Short Hydrogen Bond. X-Ray Crystal Structure of KF· $\left(\mathrm{CH}_{2} \mathrm{CO}_{2} \mathrm{D}\right)_{2}$. J. Chem. Soc., Dalton Trans. 1981, 2141-2143.

44. Bondi, A., Van Der Waals Volumes + Radii. J Phys Chem-Us 1964, 68, 441-451.

45. Chen, Y.; Ozaki, Y.; Czarnecki, M. A., Molecular Structure and Hydrogen Bonding in Pure Liquid Ethylene Glycol and Ethylene Glycol-water Mixtures Studied Using NIR Spectroscopy. Phys. Chem. Chem. Phys. 2013, 15, 18694-18701. 